\title{
Dual Degree Social Work Programs: Where are the Programs and Where are the Graduates?
}

\author{
Shari E. Miller \\ Karen M. Hopkins \\ Geoffrey L. Greif
}

\begin{abstract}
This article presents results of an exploratory study designed to survey the dual degree graduates of one large school of social work, and to report on the prevalence and types of dual degree programs offered at accredited schools of social work in the U.S. Quantitative and qualitative data were gathered from 72 dual degree graduates. Income, career trajectories, identification with social work, satisfaction with the decision to obtain a dual degree, whether graduates would encourage others to follow the dual degree path, and implications for the social work profession and social work education are discussed.
\end{abstract}

Key Words: Dual degrees; social work education; interdisciplinary study; job market

How prevalent are dual degree programs? And what happens to the graduates of these programs after they complete their studies? Though the number of dual degree programs linking social work and other professions continues to grow, little published research exists about the prevalence of these programs and the impact of such an education on the social work graduate's professional development. This article presents the results of a two fold-exploratory study including findings from a web site search of all Council on Social Work Education (CSWE) accredited masters programs (CSWE, 2003) to determine which schools offer dual degree programs, what types of dual degree programs they offer and whether programs have proliferated between 2005 and 2007, as well as the findings from a survey mailed in 2005 to 181 dual degree graduates from one school of social work's multiple dual-degree programs. The dual degree programs offered by this large urban school of social work are consistent with the types of dual degrees found in other urban social work schools. Therefore, the authors were interested in learning if these graduates are pleased with their decision to pursue a dual degree, to what extent they are using their MSW and their other degree, what advice they might have for other social work students considering the dual degree, and the implications for teaching in social work.

\section{INTERDISCIPLINARY EDUCATION AND DUAL DEGREE PROGRAMS}

Interdisciplinary education can be understood as the precursor to dual degree education. Combining fields of study reaches back, in the broadest sense, to a liberal arts education (Brubacher \& Rudy, 1976). The early scientists/philosophers, trying to understand the nature of the universe, sought new and crosscutting contexts in which to locate their areas of inquiry. Obtaining multiple degrees by studying at different universities or in different departments was common practice for hundreds of years. Interprofessional education was less common however because other than theology, law, and

Shari E. Miller PhD is an assistant professor at the School of Social Work, University of Georgia, Athens. Karen M. Hopkins PhD is an associate professor and Geoffrey L. Greif DSW is a professor at the School of Social Work, University of Maryland, Baltimore. 
medicine, professions per se were virtually non-existent prior to the mid-19th century (Stein, 1968), as was graduate education. Graduate education for the professions and in other areas of study blossomed in the U.S. after the Civil War when American society became increasingly industrialized, urbanized, specialized, and secularized (Brubacher \& Rudy, 1976, p. 177). By the beginning of the 20th century, graduate degrees were being offered by fifteen major graduate schools (Brubacher \& Rudy, 1976, p. 193) as professional schools, which often were free standing, began to attach themselves to universities. It is only relatively recently that universities and departments began to join together to offer distinct programs of study that eliminate specific course overlap by transferring in credits from one program to the other. These programs provide a more formalized means of sharing knowledge between disciplines and of preparing students for employment in an increasingly complex world. They also offer a way for graduates to become more marketable in a tight job market (McClelland, 1985). Now there are dual degree options wholly within undergraduate programs, between master's and bachelor's programs, between master's programs, between doctoral and master's programs, and between medical and $\mathrm{PhD}$. degree programs. It appears that almost every field of study holds the possibility for a dual degree. Examples of such fields are: engineering, history, fine arts, Middle Eastern and North African studies, environmental sciences, anthropology, political science, Germanic languages, criminal justice, and information sciences. For the purposes of this study only those programs offering dual degrees concurrent with the Master of Social Work degree (MSW) have been considered. The MSW and PhD in Social Work continuum has not been considered.

The sharing of information between professions has long been common in the form of transdisciplinary work (e.g. Tourse, Mooney, Kline, \& Davoaren, 2005), collaborations (e.g. Forgey \& Colarossi, 2003), and interdisciplinary studies, with some universities offering degrees in interdisciplinary studies. Universities promote interdisciplinary collaboration between their departments and schools to foster academic collegiality and to lay the groundwork for interdisciplinary grants. When it comes to a little understood profession like social work, interdisciplinary collaboration requires a specific delineation of the field's identity and of the contributions that can be made to the partnering profession (Falck, 1977). Social work faculties have called for collaboration with other professions for years (Reichert, 1970). For other fields, social work can help to foster a holistic or ecological view of the client (e.g. Lee, 2005; Meenaghan, 1984), an awareness of the interdependency of practice (Falck, 1977), and offer a social justice perspective. Collaborations work best, Dana and Sheps (1968) argue, when the schools or departments involved actualize interprofessional behavior. For example, a law clinic where social work students are placed would compel lawyers and social workers to understand each other's work more clearly than if interaction only occurred in a classroom setting.

The impact of other fields' knowledge on social work has also long been acknowledged. Boehm in the early 1970s, noted that

Increasingly...schools are moving to the position that courses in related fields of practice such as urban planning or public administration or in theory such as sociology, economic, or psychology, if their content is consistent with the educational goals and philosophy of social work, should become available to students (1971, pp., 260-261). 
Berg-Weger and Schneider (1998) surveyed accredited graduate and undergraduate social work programs and found two-thirds of the respondents had interdisciplinary collaborations (though not specifically dual degree programs) that spanned research, community service, and teaching. Sociology/social science was the most common with psychology/psychiatry being a close second. Thus sharing of information between disciplines is common and is shaped by a variety of formal and informal structures. Here the focus is on the more formal structures that lead to the granting of two combined degrees.

\section{REVIEW OF THE LITERATURE}

Little published research focused on social work dual degree programs is available. In the earliest identified article published over thirty years ago Hartford (1976) described the University of Southern California's MSW/MPA program with its focus on gerontology, which was initiated for the purposes of meeting the needs of an increasingly aging population. She outlined the different skills needed in each profession and the steps taken to socialize students to two different skill sets. A capstone, integrating seminar that included community practitioners from both fields was seen as a key element of the educational process.

McClelland (1985) described the inner workings of a joint MSW/MPH degree at the University of Minnesota. As compared with serial degrees (first one than the other), he argued, a combined program reduces overlap and allows for more active integration of material. A danger though, he pointed out, is that social workers will identify with the higher status degree upon graduation. He also pointed out potential conflicts with dual degrees in relation to application. For example, with regard to the MSW/JD, the understanding of confidentiality for the social worker is different from the privileged information gained by the lawyer. For those students who have undertaken the MSW/MBA dual degree, he stated that, "students who have attempted to combine social work with business administration have noted the lack of a code of professional ethics in business. They experience conflicts over questions of social responsibility and interdependence, especially in regards to unanticipated negative impacts of business decisions on innocent people." (p. 24). Canda (2005) raised similar issues about the combining of divinity and social work. His concern was that practitioners in any one religion might believe in proselytizing, something the National Association of Social Workers (NASW) Code of Ethics forbids.

A survey of 182 Jewish communal agency directors was designed to determine, among other things, how important dual degrees were when considering potential employees in hiring decisions. While graduate education was ranked as highly important, a second degree was viewed as not nearly as important as personality and work experience in the field (Bubis, Phillips, Reitman \& Rotto, 1985.)

Ruth, Wyatt, Chaisson, Geron, \& Bachman (2006) compared 30 of Boston University's MSW/MPH graduates with 30 MSW-only graduates. They found no significant differences between the two groups in terms of salaries and career satisfaction.

Nelson-Becker (2005) compared 45 social work and divinity dual degree graduates with $36 \mathrm{MSW}$-only graduates. One of the differences in the groups was that the dual degree graduates were more apt to inquire about the religious views of their clients leading her to conclude that, "a dual degree does make a difference in social work" (p. 123). 


\section{METHODOLOGY}

This study is exploratory in nature, designed to provide a foundation for future research regarding social work dual degree programs. To begin to lay a foundation, multiple modes of data collection were utilized including: archival research and a selfreport survey that contains both quantitative and qualitative type questions. The research focus is two-fold: (1) to present a picture of the current distribution of dual degree programs at accredited Masters conferring schools of social work and, (2) to survey graduates from one large school of social work's dual degree programs about their experiences, job trajectories and demographic characteristics.

\section{The Web Search Sample}

For the purposes of the web search, the sample included the web sites of all CSWE accredited masters programs based on 2003 data (CSWE, 2003). Thus, the total sample for the web survey included the web sites of 167 accredited social work programs (including branch campuses).

\section{The Survey Sample}

The participants included the graduates of one large mid-Atlantic school of social work's dual degree programs spanning thirty-two years (1973 through 2005). The four dual degree options offered through the social work program are: MSW/MA (Jewish Studies), MSW/JD, MSW/MBA, and MSW/MPH. These programs are each structured differently and are located extra-university (with another university), intra-university (with another school on the same campus) and, inter-university (with another school that is part of the same university system but is on a different campus) depending upon the dual degree option.

The sample included a total of 227 dual degree graduates. Of those 227, contact information for 46 was inaccurate and not able to be updated. Thus, the total sample included 181 alumni who graduated between 1973 and 2005. Of the 181 surveys mailed, 72 were returned (40.0\% response rate). Archival data for a random sample $(60.2 \%)$ of the total sample was searched to gather information about the characteristics of the dual degree graduates to determine if there were any differences between those who responded to the survey and those who did not. Findings of that search will be discussed later in the article. Because the MSW/MA program is the longest standing of the four programs, a majority of the respondents graduated with that dual degree. The MSW/MPH program, with the fewest respondents, graduated its first student in 2003. Of the 72 respondents, $75.0 \%$ graduated with the MA, followed by $18.0 \%$ with the JD, $6.0 \%$ graduated with the MBA and lastly, $1.0 \%$ with the MPH

\section{The Web Search Procedure}

Initially, in the fall of 2004, the authors contacted CSWE to request their most recent data on dual degree programs. The data were received through a personal email 
communication in the form of an EXCEL database (personal communication, November 2004). Then, all CSWE Accredited Master of Social Work programs were identified using CSWE's 2003 listing. The web site for each of these programs was located using the Google search engine. The process of searching each web site varied depending upon the web site's design. Information about dual degree programs was located in different places on different web sites. If no link to dual degree program information appeared on the home page, the link to academic programs was followed, when such a link appeared. Following the academic programs link in some cases led to further links specific to dual degree programs. If no relevant information or link to dual degree programs could be found, the search option was utilized when available. Search terms included, dual degree, joint degree, concurrent degree, and programs. If a search option did not exist on the particular school of social work's web site, the entire University's web site was searched using the same combinations of search terms as above, as well as the search terms, social work, MSW, and Masters in Social Work. If all search avenues led to no matches, it was understood that dual degree programs were not offered through that school of social work.

When dual degree programs were noted to exist at a school of social work, all links to respective programs were followed. The University and its dual degree offerings were then logged in a table. Once all 167 web sites were searched, and complete data were synthesized, the set of dual degree offerings was organized by type of degree and University in an EXCEL database.

\section{The Survey Procedure}

A 24-item self-report survey was created for the purposes of this study. A combination of qualitative and quantitative questions centered on, respondents' work history and professional affiliation, whether or not they believed the dual degree had helped them, whether one of the degrees has been more beneficial over the course of employment than the other, the reasons they chose to pursue a dual degree, whether they had any advice for dual degree graduates, and their demographic background.

After IRB approval, the survey was initially mailed to respondents in May 2005 with a cover letter indicating that surveys were confidential but not anonymous. Surveys were coded and paired with a list of respondent names for the purpose of facilitating follow-up mailings. The letter also indicated that the respondent would receive a second mailing of the survey in the event that they did not return the first. Because 76 of the initial surveys mailed were returned due to change of address, a subsequent set of first mailings was sent when updated contact information could be obtained for those respondents. Updated contact information was located for 30 of the 76 returned, thus 30 surveys were re-sent. Subsequently, the second round of mailings was sent in July 2005 to all those who had not responded to the initial mailing. Once completed surveys were received, data were entered into an SPSS database. Descriptive and bivariate statistical analyses were performed. An alpha level of .05 was used for bivariate analyses.

The survey contained qualitative questions designed to gather more detailed and subjective information from respondents about their dual degree experiences. Following Weber (1990) content analysis was applied to written responses to the four open-ended questions. Responses were organized under themes that emerged from the data, and the 
number of responses under each theme was counted to determine the intensity of participants' experiences.

\section{The Web Search Findings}

\section{RESULTS}

In reviewing the data received via an email communication with CSWE, (personal communication, November 2004) the web search revealed that the data collected by CSWE is not current. As of January 2005, 58 of the 167 schools of social work (34.7\%) offered at least one dual degree program, with 35 schools (20.9\%) offering two or more. In February of 2007, in order to learn how rapidly programs were growing, a randomly selected $10 \%$ of the original 167 schools' websites were re-searched (six of those schools that offered programs and 11 of those that did not) to see if the schools that had programs were maintaining them and/or continuing to develop them, and if those that did not had started any. By 2007, the number had increased. One additional school had developed a dual degree program in social work and law for a total of 59 schools offering programs (35.3\%). Those schools that had dual degree programs in the previous search have maintained them and in one case two programs have been added. In January of 2005 there were a total of 48 different dual degree options - by February of 2007 there were 49. Some of these degree options bear similar titles, however are considered separately as the degree titles vary slightly (i.e., Urban Planning and Urban and Regional Planning, or Pastoral Studies and Pastoral Counseling). The most common program is the MSW/JD, followed by the MSW/MPH, MSW/MDiv and the MSW/MBA. Table 1 lists the nine most frequently occurring dual degree programs and the percentage of the 59 schools that offer each program. The criterion for inclusion in Table 1 is that the program was offered at $5 \%$ or more of the 59 schools at the time of data collection. Percentage data for all 49 of the dual degree programs located in this search is available from the authors. Other dual degree options include bio-ethics, Pan-African studies, city and regional planning, architecture, government administration, child development, sociology, gerontology, health administration, information science and women's studies, to name some. The web search also revealed that dual degree programs are offered at schools of social work throughout the country, that range in size from small (under 50 graduates per year) to large (over 150 graduates per year) (Lennon, 2004).

\section{The Survey Findings}

Descriptive and bivariate statistical analyses were performed; however, the solitary MPH graduate was not included in the bivariate analyses. Tables 2 through 4 summarize the descriptive data.

Demographics. Seventy-two dual degree respondents completed a survey, of which 52 (73\%) were female and $65(91 \%)$ were white. These statistics are representative of the total sample that also included $73 \%$ women and $90 \%$ white students. The sample contained fewer females and more white students than does the overall student body, which is approximately $80 \%$ female and $66 \%$ white. About half $(38,53 \%)$ of the respondents were older than 40, with a mean age of 41 years. Almost $20 \%$ of the respondents reported annual earnings of less than $\$ 30,000$ dollars, another $26 \%$ reported earnings of more than $\$ 100,000$, and the remaining respondents reported earning amounts somewhere within that 
Table 1

Most Frequently Offered Dual Degree Programs by Percent

\begin{tabular}{lc}
\hline Type of program & $\%$ Of schools offering program \\
\hline Juris Doctorate & $62.7 \%$ \\
\hline Master of Public Health & $34.5 \%$ \\
\hline Master of Divinity & $31.0 \%$ \\
\hline Master of Business Administration & $20.7 \%$ \\
\hline Master of Public Affairs & $15.5 \%$ \\
\hline Master of Arts in Jewish Communal Service & $6.9 \%$ \\
\hline Master of Public Policy & $6.9 \%$ \\
\hline Master of Science in Education/Special Education & $6.9 \%$ \\
\hline Master of Criminology and Criminal Justice & $5.2 \%$
\end{tabular}

Note. Percentages are based on the total number of schools of social work that offer dual degree programs.

Table 2

Summary of Descriptive Data by Dual Degree: Demographics

\begin{tabular}{|c|c|c|c|c|}
\hline Survey Items & $\begin{array}{l}\text { MSW/MA } \\
(\mathrm{n}=54)\end{array}$ & $\begin{array}{l}\text { MSW/JD } \\
(\mathrm{n}=13)\end{array}$ & $\begin{array}{l}\text { MSW/MBA } \\
(\mathrm{n}=4)\end{array}$ & $\begin{array}{l}\text { MSW/MPH } \\
(\mathrm{n}=1)\end{array}$ \\
\hline Female & $41,76 \%$ & $10,77 \%$ & $2,50 \%$ & 0 \\
\hline Gender & & & & \\
\hline Male & $13,24 \%$ & $3,23 \%$ & $2,50 \%$ & $1,100 \%$ \\
\hline Mean Age (years) & 41 & 37 & 33 & 31 \\
\hline Mean Annual Income & $\$ 82,000$ & $\$ 75,000$ & $\$ 95,000$ & $\$ 55,000$ \\
\hline Median Annual Income & $\$ 75,000$ & $\$ 65,000$ & $\$ 80,000$ & ---------- \\
\hline $\begin{array}{lll}\text { Annual } & \text { Income } & > \\
\$ 100,000 & \end{array}$ & $10,19 \%$ & $3,23 \%$ & $1,25 \%$ & 0 \\
\hline $\begin{array}{lll}\text { Current } & \text { Social } & \text { Work } \\
\text { License } & & \\
\end{array}$ & $13,24 \%$ & $4,31 \%$ & 0 & 0 \\
\hline MSW & $7,13 \%$ & $8,62 \%$ & $2,50 \%$ & $1,100 \%$ \\
\hline $\begin{array}{l}\text { Clinical } \\
\text { Concentration: } \\
\text { Macro }\end{array}$ & $47,87 \%$ & $5,38 \%$ & $2,50 \%$ & $1,100 \%$ \\
\hline
\end{tabular}

range. The mean income reported was $\$ 60,000$. Only 17 (24\%) of the dual degree respondents currently hold a social work license although 31 (45\%) were licensed in the past. The majority (78\%) of dual degree respondents enrolled as "out-of-state" students when they applied for admission to the MSW program.

Dual degrees. Fifty-four (75\%) of the MSW's were awarded an MA dual degree, 13 (18\%) earned a JD degree, 4 (6\%) had an MBA, and 1 received an MPH (1\%). The respondents graduated between 1974 and 2005 with 1989 representing the mean year of graduation. There was a significant $(\mathrm{p}<.05)$ difference in the type of dual degree by respondents' age. Those who were 40 or older were more likely than younger respondents to have obtained an MA degree instead of the JD and MBA degrees. There were no other significant differences among respondents in terms of age and year of graduation related to 
Table 3

Summary of Descriptive Data by Dual Degree: Current Employment

\begin{tabular}{|c|c|c|c|c|}
\hline Survey Items & $\begin{array}{l}\text { MSW/MA } \\
(\mathrm{n}=54)\end{array}$ & $\begin{array}{l}\text { MSW/JD } \\
(\mathrm{n}=13)\end{array}$ & $\begin{array}{l}\mathrm{MSW} / \mathrm{MBA} \\
(\mathrm{n}=4)\end{array}$ & $\begin{array}{l}\text { MSW/MPH } \\
(n=1)\end{array}$ \\
\hline \multirow[t]{2}{*}{ Degree Primarily Used } & MSW $=52 \%$ & $\mathrm{MSW}=38 \%$ & $\mathrm{MSW}=25 \%$ & $\mathrm{MSW}=0 \%$ \\
\hline & $\mathrm{MA}=48 \%$ & $\mathrm{JD}=62 \%$ & $\mathrm{MBA}=75 \%$ & $\mathrm{MPH}=100 \%$ \\
\hline \multirow[t]{3}{*}{ Work Setting: } & $1,2 \%$ & $6,46 \%$ & $0 \%$ & $1,100 \%$ \\
\hline & $36,67 \%$ & $2,15 \%$ & $3,75 \%$ & $0 \%$ \\
\hline & $8,15 \%$ & $5,38 \%$ & $1,25 \%$ & $0 \%$ \\
\hline $\begin{array}{l}\text { Director/Upper } \\
\text { Management Position }\end{array}$ & $32,59 \%$ & $5,38 \%$ & $3,75 \%$ & 0 \\
\hline
\end{tabular}

Note: 7 (9.7\%) of respondents are currently unemployed.

Table 4

Summary of Descriptive Data by Dual Degree: Career Trajectory

\begin{tabular}{|c|c|c|c|c|}
\hline Survey Items & $\begin{array}{l}\text { MSW/MA } \\
(\mathrm{n}=54)\end{array}$ & $\begin{array}{l}\text { MSW/JD } \\
(\mathrm{n}=13)\end{array}$ & $\begin{array}{l}\text { MSW/MBA } \\
(n=4)\end{array}$ & $\begin{array}{l}\text { MSW/MPH } \\
(n=1)\end{array}$ \\
\hline \multicolumn{5}{|l|}{ First Work Setting: } \\
\hline Public & $0,0 \%$ & $7,54 \%$ & $0 \%$ & ---- \\
\hline Nonprofit & $52,96 \%$ & $5,38 \%$ & $1,25 \%$ & \\
\hline For-profit & $2,4 \%$ & $1,8 \%$ & $3,75 \%$ & \\
\hline $\begin{array}{l}\text { First Job: } \\
\text { Management Position }\end{array}$ & $26,48 \%$ & 0 & $3,75 \%$ & ---------------- \\
\hline Mean Years in First Job & 4.86 & 3.31 & 1.62 & ------------------ \\
\hline $\begin{array}{l}\text { Both Degrees Equally } \\
\text { Beneficial }\end{array}$ & $41,80 \%$ & $11,85 \%$ & $3,75 \%$ & \\
\hline
\end{tabular}

the type of dual degree they selected. The majority $(53,77 \%)$ of the respondents were enrolled in the social work "macro" concentration while pursuing their dual degrees.

Current employment. As shown in Table 3, more dual degree respondents are currently employed in the not-for-profit sector $(41,65 \%)$, than in the for-profit $(12,19 \%)$ and public $(8,13 \%)$ sectors. Specifically by dual degree MSW/MA's and MSW/MBA's were more likely $(\mathrm{p}<.0001)$ than other respondents to be employed in the not-for-profit sector; MSW/JD's were more likely $(\mathrm{p}<.0001)$ than other respondents to work in the public sector. Fifty-six percent of dual degree respondents in the not-for-profit sector make over $\$ 50,000$ compared to $21 \%$ in the public sector, and $24 \%$ in the for-profit sector. As mentioned, $19 \%$ of the respondents reported earning over $\$ 100,000$. Of those 14 , most were men (64\%), over 40 years old (79\%), who hold an MSW/MA dual degree (71\%), and work in a senior management position (100\%). Half of the higher earners work in the notfor-profit sector (50\%), and the rest work in the for-profit sector. Seven respondents reported being currently unemployed; six of those were women who dropped out of the workforce to care for young children.

Over half of all the survey respondents (40, 61\%) currently hold management positions (i.e., executive director, vice-president, etc.) within their employment settings. 
These management positions are significantly more likely to be held by respondents who are male $(86 \%, \mathrm{p}=.01)$, who have an MSW/MA dual degree $(80 \%, \mathrm{p}<.01)$, and who make over $\$ 50,000(76 \%)$, $\mathrm{p}<.01)$.

The respondents were almost equally divided in reporting that they are currently employed primarily in the social work field (53\%) or in the field that corresponds to their other degree (47\%). Younger respondents (under 40$)$ were more likely $(p=.01)$ than older respondents to report that they were employed in a setting primarily using their "other" degree. Additionally, respondents working in settings primarily using their other degree were significantly less likely $(\mathrm{p}<.0001)$ than those in the social work field to have a current social work license.

Career trajectories. Many of the dual degree respondents reported an employment history that included moving to several different job settings over time. The mean number of years that 68 (94\%) dual degree respondents spent in their first job after graduating with a dual degree was four years. Sixty-one of those respondents moved to a second job and remained for a mean of 4.5 years. Another 48 moved to a third work setting for a mean of 5.6 years. Thirty-one of those respondents took a fourth job and stayed for a mean of 6.5 years. Finally 22 more respondents obtained a fifth job remaining for a mean of 5 years. Most of the respondents $(55,81 \%)$ reported that both degrees were equally beneficial to their career. The data indicated that there were no differences among respondents by gender, age, or type of dual degree regarding the amount of time they remained in their first job.

Interestingly 30 (42\%) of the respondents were hired into management positions for their first job after graduating with a dual degree. Most of these respondents had an MSW/MA degree (87\%) with equal percentages (50\%) of men and women in management positions early in their careers. This suggests that men and women with dual degrees (particularly the MSW/MA) start out with similar opportunities for leadership positions but more men than women either stay in management or are promoted into these positions over time.

Nonresponse bias. There appeared to be no differences between respondents who returned the survey and nonrespondents by gender, race, age, or degree. There was however a significant difference between respondents and nonrespondents by "year graduated” with the dual degree. The respondents who graduated earlier, prior to 1989, were more likely $(p<.05)$ to return surveys than respondents who graduated in 1989 or later further contributing to the higher number of respondents with the MSW/MA dual degree.

Survey Qualitative Findings

The survey contained four qualitative questions including a) reason(s) for selecting a dual degree, b) how the dual degree education was financed, c) whether or not respondents would encourage others to pursue a dual degree and why, and d) "words of wisdom” for students who might be considering a dual degree program. The number of respondents who chose to answer each question varied slightly with 71 (98.6\%) respondents answering the first, 72 (100\%) answering the second, 69 (95.8\%) answering the third, and 52 (72.2\%) answering the fourth. Because there was only one MSW/MPH respondent the majority of the data discussed applies primarily to the MSW/MA, MSW/JD, and MSW/MBA respondents. 
For the first question "what was your reason for selecting a dual degree?" some themes emerged that were consistent across the dual degree programs, in addition to other themes that were program-specific. Across all programs three primary reasons for selecting a dual degree were, the flexibility that having both degrees might provide in the job market, enhanced marketability/more competitive resume, and the multiple perspectives provided by the two degrees. Some discipline-specific themes that emerged included, for JD's, a desire to do advocacy and promote social change as a motivating factor, for MBA's, the wish for enhanced interpersonal skills and the desire to engage in non-profit leadership, and for the MA's, the desire to do social work specifically in a Jewish setting.

Regarding the second question "how did you finance your dual degree education?" student loans, part-time employment, familial/parental support, and savings were noted as the key means of financing across dual degree programs. Scholarships/fellowships/grants were also mentioned by 65\% of the MA's but only rarely by the JD’s and MBA's.

In response to the third question "would you encourage others to pursue a dual degree? Why?" 69 (95.8\%) of the respondents said "yes", while three of the 72 respondents (4.1\%) said "no" - the three negative responses came from JD's. Again, some consistent themes emerged across disciplines among those respondents who said "yes" including, the opportunity to integrate interests and talents, the benefit of multiple perspectives and a wider skill set to broaden thinking and problem-solving approaches, increased marketability and competitiveness in the job market, and a wider array of job opportunities. Some discipline-specific thoughts among those who said yes were that, for JD's, social work and law provide a good balance, for MBA's, “anyone can make use of strong business skills", and for the MA's, the dual degree "gives professional shape to a passion”, provides excellent preparation for Jewish communal work, and provides a core peer group of fellow students from whom to draw support. Lastly, among the three JD's who said "no they would not encourage others to pursue a dual degree", the key reasons were that, "it is impossible to practice certain kinds of law and social work together", it is "extremely difficult to use both degrees at once", and "for most, the MSW ensures a low paying law job”.

Regarding the fourth question, "can you offer any 'words of wisdom' to students who might be considering a dual degree program?” many of the respondents began their responses by saying, "go for it”. Again, a series of themes emerged both across disciplines and also within individual disciplines. One response that was consistent was to carefully consider career goals before beginning a program and to do research related to those career goals and the relevance of the dual degree before engaging in the program. Other emergent themes were, to be aware of costs, to learn how to advocate within the administration of both programs, and to use time management skills. A number of additional thoughts emerged within each different program - only those that appeared most frequently are discussed. For JD's, the idea of staying connected to the school of social work and the values of the social work profession was a recommendation. For MBA's there emerged the theme that the "MBA is more highly valued on the market than the MSW" and in some cases, the MSW was misunderstood and not appreciated in the business world. For MA's a frequent recommendation was to focus on the field placement and to be sure to apply skills learned in both sets of classes to the field. Another recommendation specific to the MA's was that relationships to fellow dual degree students are very important - it was noted that "single degree students" could not relate to the experience. 


\section{Implications}

\section{DISCUSSION}

The purpose of this study was to determine the prevalence of social work dual degree graduate programs, whether they are proliferating, and to assess what happens to the graduates of these programs after graduation. Findings provide insight into the experiences and career paths of MSW graduates with a dual degree. Based on the longitudinal outcomes of the web search, it appears that dual degree programs continue to proliferate. As educational and professional opportunities for graduates grow in kind, it is important to understand the career trajectories of those who have graduated and the implications for social work and dual degree education.

The overwhelming majority of dual degree graduates (95.8\%) would recommend dual degree programs to other students. Though a high percentage of JD's and MBA's reported that they are using their "other" degree more in their current position $93.4 \%$ of the sample noted that their MSW was equally as beneficial or more beneficial to them during the course of their whole career. These findings have implications for marketing and recruiting activities. While dual degree programs are proliferating based on the data gathered for this study, the proportion of students graduating from dual degree programs is comparatively small. One reason may be the difficulty in locating dual degree program information on some of the social work schools' web sites. This study demonstrated that web searches did not always lead down intuitive paths. Students making their way to MSW programs may not even know the dual degree option exists so will not know to look for it. Perhaps NASW could include a link to information regarding dual degree programs on their website to inform perspective students. Information provided by NASW would be contingent upon each school keeping their program information up to date and available. Since one of the findings indicated that a significant proportion of dual degree students came from out of state, and so are potentially searching nationally for a program that best fits their needs, it makes sense for schools to include a link in an easily accessible space on their web sites. It would be helpful if schools of social work kept CSWE abreast of their dual degree programs so that data on the nature and growth of these programs can become more accessible.

Other implications for social work and dual degree education are related to integration of programs, faculty involvement, licensure, career paths in management, and income. A number of respondents in this sample recommended that it is essential for dual degree students to advocate for themselves with the administrations of both programs. It seems that administrative and curricular efforts to join the two programs might make for an enriched dual degree experience. Potential options include an integrative seminar (offered at some universities and advocated for by Canda (2005)) that provides an opportunity for students to share in a collective experience, or, an enhanced administrative structure that supports communication between the two programs and alleviates the need for students to have to advocate for themselves. Giving consideration to the way in which programs are integrated could contribute to how students identify with, integrate, and utilize both degrees jointly.

Based on the updated website search, an increasing number of schools of social work offer a dual degree option(s). As such, information about dual degree-oriented 
students' needs should be of interest to social work faculty. There are a number of issues for students to negotiate when they are simultaneously enrolled in two programs, or perhaps two institutions, and having faculty available for focused feedback or advice may be important for dual degree students' success. Social work faculty can play a pivotal role in helping dual degree students make clear conceptual and practical linkages between programs of study. For example, in the classroom social work faculty can encourage dual degree students to share relevant information or experiences from "other degree" coursework that can inform or enhance discussion.

Few respondents in this sample have a social work license. Many of the dual degree graduates reported a macro (vs. clinical) concentration while in school, and many took on management positions immediately after graduation. As a result they may not have considered licensure a necessary path. Because the licensing requirements are changing such that licensure is expected and encouraged for all social workers this will be an important activity to track. Over time dual degree graduates may be just as likely to obtain social work licensure as non-dual degree graduates and this may contribute to the strength of their continued identification with the social work profession.

Given the high percentage of dual degree graduates in nonprofit management positions it is also important to make sure dual degree students are exposed to relevant administrative coursework during their social work education to adequately prepare them for these types of positions. Unlike Ruth et al's (2006) findings, this study did locate some potential differences between dual degree and MSW-only graduates. Besides the seemingly increased opportunities for management positions the mean salaries of dual degree graduates in this sample $(\$ 60,000)$ are reported to be higher than the NASW published mean for social workers $(\$ 47,200)$. Therefore perhaps more social work students may opt to pursue a dual degree education.

\section{Limitations}

While the researchers attempted to do a comprehensive search of the web sites of all accredited Master of Social Work programs and of those programs in candidacy, it is possible that some of the web searches may not have located all dual degree offerings. Because this search was web-based and did not include direct contact with each University it is possible that the information gathered from web sites was not current. In addition, this study was exploratory in nature as there is a paucity of published research regarding dual degree programs in social work. The overall sample was small and the study captures the experiences of graduates from one school of social work's dual degree programs so findings may not be representative. However the school is one of the largest schools of social work in the country and serves an urban and rural statewide population.

Because the four dual degree programs offered each emerged at different points in time the number of graduates from each degree grouping varied significantly with the overwhelming number representing one dual degree experience. It was not possible to utilize sophisticated statistical techniques to analyze the data and to make comparisons across degrees. Another limitation of this approach is that the survey may more likely have been returned by those who continue to identify with the social work profession, or those who had a positive dual degree experience, and therefore might not fully represent the experience of the dual degree graduates. 


\section{Future Research}

Because there has been such limited research around dual degrees in social work further research is needed to explore the experiences (both during and beyond the course of study) and the job trajectories of social work dual degree graduates. Future studies should include alumni surveys similar to the one discussed herein as well as national surveys designed to gather cross-sectional data about dual degree graduates and the designs of dual degree programs.

One issue about which little is known includes the structure and potential impacts of sequencing of the dual degree programs, meaning, in which order students take courses in each of the programs. For example it would be helpful to see if those who started or ended one program first tilted their career in one direction or the next.

The MSW/JD is the most frequently occurring dual degree program and there has been no documented research on this group of students. Of the participants in this study the only ones to respond in the negative to the question of whether they would recommend a dual degree were the JD's. There seemed to be a perception by some JD respondents that the two professions are mismatched in certain ways and cannot be combined effectively. One concern in particular was related to the potentially conflicting value systems. MBA's also noted some potential discontinuity between value systems. Both of these findings support McClelland's (1985) concerns. It would be useful to explore the perspectives of these students further to gain an understanding of their experiences while in the dual degree programs and also in the work world.

Because research in the area of social work dual degrees is sparse, yet dual degree options appear to be proliferating, it is essential for the profession to tease apart what variables impact satisfaction with these programs. Some variables to consider include: sequential structure, licensure, perceived professional status, income potential, and the nature of coursework.

In describing how social work's influence is being diminished in policymaking circles, Reisch (2006) warns, "graduates from other disciplines, such as public policy, business, law, and public health, are increasingly favored for such jobs over their social work counterparts." If this is the case, dual degrees are one way for social workers to continue to have an influence. In an increasingly well-educated society where there is a growing focus on inter-disciplinary collaboration, multiple degrees will likely be a constant. With its history of collaborative effort, and with its broad scope of practice options, social work is well positioned to benefit from dual degree programs and to contribute to their evolution - let's understand how to make our programs as strong as possible. 


\section{References}

Berg-Weger, M., \& Schneider, F. D. (1998). Interdisciplinary collaboration in social work education. Journal of Social Work Education, 34, 97-107.

Boehm, W. W. (1971). Education for social work. In Encyclopedia of Social Work. (Vol. 16, pp. 257-273). New York: NASW Press.

Brubacher, J. S., \& Rudy, W. (1976). Higher education in transition: A history of American colleges ad universities, 1636-1976. New York: Harper \& Row.

Bubis, G. B., Phillips, B. A., Reitman, S. A., \& Rotto, G. S. (1985). The Consumer Reports: Hiring of entry-level Jewish communal workers. Journal of Jewish Communal Services, 62, 103-110.

Canda, E. R. (2005). Integrating religion and social work in dual degree programs. Journal of Religion and Spirituality, 24, 79-91.

Council on Social Work Education. (2003). Directory of colleges and universities with accredited social work degree programs. Alexandria, VA: Author.

Dana, B., \& Sheps, C. G. (1968). Trends and issues in interprofessional education: Pride, prejudice, and progress. Education for Social Work, 4, 35-41.

Falck, H. (1977). Interdisciplinary education and implications for social work practice. Journal of Education for Social Work, 13(2), 30-37.

Forgey, M. A. \& Colarossi, L. (2003). Interdisciplinary social work and law: A model domestic violence curriculum. Journal of Social Work Education, 39, 459-476.

Hartford, M.E. (1976). The MSW-MPA dual degree program in gerontology: A new model for the preparation of social work administrators. Journal of Education for Social Work, 12(3), 51-58.

Lee, D. B. (2005). Conclusion: Current state of social work and divinity dual degree programs. Journal of Religion and Spirituality in Social Work, 24, 137-155.

Lennon, T.M. (2004). Statistics on social work education in the United States: 2002. Alexandria, VA: Council on Social Work Education.

McClelland, R. (1985). Joint degrees: Do they strengthen or weaken the profession? Journal of Social Work Education, 21(1), 20-26.

Meenaghan, T. M. (1984). Using social work curriculum in socially oriented architecture programs. Journal of Social Work Education, 20(2), 71-79.

Nelson-Becker, H. B. (2005). Does a dual degree make a difference in social work: An empirical study. Journal of Religion and Spirituality in Social Work, 24, 111-124.

Reichert, K. (1970). Current developments and trends in social work education in the United States. Journal of Education for Social Work, 6(2), 39-50.

Reisch, M. (2006). Workforce study falls short. Social Work, 51, 291-293.

Ruth, B. J., Wyatt, J., Chaisson, E., Geron, S. M., \& Bachman, J. (2006). Social Work and Public Health: Comparing graduates from a dual-degree program. Journal of Social Work Education, 42, 429-439.

Stein, H. (1968). Professions and universities. Journal of Education for Social Work, 4(2), 53-65.

Tourse, R. W. C., Mooney, J. F , Kline, P., \& Davoren, J. (2005). A collaborative model of clinical preparation: A move toward interprofessional field experience. Journal of Social Work Education, 41, 457-477.

Weber, R. P. (1990). Basic content analysis (2nd. Ed.). Newbury Park, CA: Sage. 


\section{Author's note:}

Address correspondence to: Shari E. Miller PhD, School of Social Work, The University of Georgia, Tucker Hall, 310 East Campus Road, Athens, GA 30602. E-mail: semiller@uga.edu. 